\title{
Utilizing BIM In A Design-Build Competition Program
}

\section{Mr. Norman Henry Philipp, Pittsburg State University}

Norman's professional work experience includes consulting and lecturing on BIM, architecture, architectural engineering, design-build, acoustics and project management. Mr. Philipp has dual bachelors and dual masters degrees in the fields of Architecture and Architectural Engineering. He received his PE in Architectural Engineering from the State of Kansas in 2013. His course work includes building information modeling, BIM management, construction graphics, building systems, engineering project management, and design-build. Mr. Philipp is CM-BIM certified through the Associated General Contractors of America. Additionally he serves as the Southeast Kansas Regional Co-Coordinator for the Kansas Disaster Assessment Team through the State of Kansas Department of Emergency Management. 


\title{
Utilizing BIM in a Design-Build Competition Program
}

\begin{abstract}
This paper highlights the hands-on participation of university students from the Pittsburg State University School of Construction towards delivering creative solutions to solving the housing problem for people displaced by various natural and man-made disasters through the designbuild "Transitional Disaster Shelter Design Competition" as hosted by John Brown University and sponsored by World Vision in 2014 and Samaritan's Purse in 2015. Construction management, engineering and architecture student teams are invited to design and construct a rapidly deployable transitional disaster shelter for use by aid organizations in response to disasters. The top ten teams are selected from the submitted entries and permitted to construct prototype shelters for testing and presentation at John Brown University. This study presents the participation of students involved though traditional phases of design and construction within a design-build methodology along with the development of business case analysis studies for mass production. The application and utilization of various BIM design, analysis and construction software packages are reviewed in their use throughout the project. The paper also reviews the curriculum for which the project was integrated and how concepts from the shelter are used in curriculum lessons learned and suggestions for future competitions are given.
\end{abstract}

\section{Introduction}

The process for what is considered engineering and construction is expanding in the ever changing global market. Engineers and professionals now have to do more than just problem solve $^{1}$. They must be able to be innovative in design and execution utilizing creative thinking along with math and science principles. They must then be able to work as interdisciplinary teams of other professional and communicate effectively across those disciplines ${ }^{1}$. From this a need for hands-on design and construction experiences has been identified within the construction, architecture and engineering education community. Consequently, the challenge for educators is create learning environments involving real-world problems that are meaningful and engaging to their students. They must "balance technical solutions with social, cultural, environmental, economic, and sustainable concerns, in an environment that features multidisciplinary peer interaction and mentoring" 5 . In response, schools have developed handson design-build studios (e.g., Studio 804 at the University of Kansas) or incorporated designbuild competitions (e.g. U.S. Department of Energy's Solar Decathlon) into their curriculums as a means of meeting this need. These types of collaborative and engaging learning opportunities are what students of the $21^{\text {st }}$ century are wanting to be involved with ${ }^{9}$.

The goal of this paper is to share the integrated nature of implementing building information modeling (BIM) software in a design-build project on a university campus - specifically the 2014 and 2015 World Vision/Samaritan's Purse and John Brown University Transitional 
Disaster Shelter Competition ${ }^{6}$. It is also to reflect on the value of utilizing hands-on design-build competitions as part of a construction management program.

\section{The Competition}

The John Brown University Transitional Disaster Shelter Competition was developed in 2012 as research and development effort to help World Vision and its field partners with their disaster relief mission to provide transitional shelters for disaster victims. In the early weeks after a disaster, either natural or man-made (e.g., earthquake, tsunami, hurricane, tornado, terrorist action) survivors may be provided with basic materials, such as tents and tarps, but transitional shelters that are safe and appropriate to the environment and culture are often needed until families can rebuild permanent homes ${ }^{6}$. The Transitional Disaster Shelter Competition calls for

entries from engineering, construction management and architecture student teams to design and construct a rapidly deployable transitional disaster shelter for use by aid organizations in response to disasters. Each team may consist of students from a single university or incorporate several different universities. Teams are required to submit a preliminary application at the start of the Spring semester. Of these a maximum of ten teams are selected from the submitted entries and invited to compete on the campus of John Brown University in Siloam Springs, Arkansas. The teams typically complete the design, construction and testing of the prototype shelter during the Spring semester. According to the official website for the Transitional Disaster Shelter Competition, "the shelter should be designed to meet the needs of a typical refugee family who are looking for shelter that may be constructed on their own property or in areas designated by local officials for temporary relocation. As much as possible, designs should take into account local conditions, specifically the environmental, social, cultural and religious needs of a family. The shelter should be considered transitional or core shelters (rather than emergency response), so that the shelter has the capacity to be added to, upgraded, altered, and modified to meet the changing needs of a family that is anticipated to be displaced for a prolonged period."

The purposes of the competition are educative, scientific, and humanitarian; working together to both educate the general public and innovate new applications and methods related to the design and construction of cost-effective, sustainable, and humanitarian housing. Collectively these ambitions promote collaboration, which may in turn lead to new technologies being applied to deployable small structures, or existing products being repurposed in creative methods. Designs are required to meet the humanitarian standards set forth in the Sphere Standards ${ }^{10}$ and other internationally accepted standards. The 2014 competition ultimately consisted of seven teams from US universities and the 2015 competition consisted of four teams from US universities and one from South Korea. Each team constructed a rapidly deployable prototype shelter with a minimum footprint of 46 square feet (14 square meters), weighing less than $440 \mathrm{lbs}$. (200 kg), costing less than $\$ 1500$ to fabricate, and able to be "flat-packed" for optimal storage and 
shipping of multiple units within an 8' x 40' shipping container. Teams and their shelters compete in several contests of varying subject matter.

- Design Report

- Business Case Presentation

- Timed Setup

- Physical Parameters

- Functionality

- Livability

- Ease of Assembly

- Thermal Retention
- Seismic Resistance

- Wind Resistance

- Water Infiltration

- Packing Ease and Size

- Upgradability

- Cultural Appropriateness

- Cost

- Business Case Analysis

One of the key reasons that this competition differs from others traditionally entered into by construction, engineering and architecture schools is the cost. At a maximum inherent value per shelter of $\$ 1500$, this competition provides an opportunity for schools of construction, architecture, and engineering to incorporate a hands-on design-build competition into their curriculum at a reasonable cost (as compared to other design-build competitions such as the U.S. Department of Energy's Solar Decathlon ${ }^{3}$ ). Additionally the lower cost allows for schools to generate multiple design-build student teams. This allows for cross-project collaboration and competition within individual schools and possibly between multiple collaborating schools.

\section{Literature Review}

There is a need to change the way engineering and construction education is being taught. Bernold $^{1}$ concludes that there is radical change needed to change the education process for the construction and engineering education process; suggesting that an active learning approach needs to be taken beyond the traditional classroom experience. Experiential or contextual learning is gaining recognition in higher education with the introduction of coursework combined with community service or civic engagement outside of the classroom ${ }^{2}$. A contextual learning program needs to include a real-world problem and a real-world organization. Just like the real-world, students must apply for the positions and opportunities to work on the project, even in the classroom setting. The project needs to include classroom as well as onsite work experience. Faculty and students need to monitor and assess what they are learning through observation, daily feedback, student journals, mentoring, and other assessment tools ${ }^{5}$. The more active the learning becomes, the more the knowledge they gain and take away from the experience $^{4}$. The Transitional Disaster Shelter Competition is an excellent and innovative way for students to combine classroom experience with onsite real-world, real time education that cannot be replicated in a classroom or lab environment. It is real-world experience that encompasses all of the ABET outcome criteria. The Transitional Disaster Shelter Competition gives students the opportunity to integrate all of those aspects in a single experience, and they're 
building something real. In the debriefing review of the 2014 competition, the faculty advisor and program coordinators observed how the competition provided an excellent vehicle for integrating many of the guidelines set forth by ABET into the learning experience.

\section{Design-Build Teams}

The 2014 Pittsburg State University (PSU) student team consisted of students from the Construction Management and Construction Engineering Technology degree programs. Two seniors were selected from the CMCET 691 Senior Projects course to serve as project managers. Additional team members included three students enrolled in CMCET 795-03 Special Topics: Disaster Shelter Design and student volunteers ${ }^{8}$. Students enrolled in the special topics course assisted the project managers with design development and contextual research. Several of the students involved were Brazilian international exchange students attending Pittsburg State University. The 2015 (PSU) student team again consisted of two seniors from the senior projects class and several students either volunteering or enrolled in the special topics course. One student participated in both the 2014 and 2015 competition teams. Additionally, it should be noted that on each of the PSU School of Construction student teams, several of the students had previously interned with Next Step Ministries and worked in post disaster areas such as New Jersey and Oklahoma.

In 2015, a second team was sponsored by the Pittsburg State University College of Technology \& School of Construction, consisting of ten students from Gyeongsang National University (GNU) in Jinju, South Korea, participating in the 2014 Korean (GNU) Innovation Engineering, Project Management \& Design Program. These students consisted of juniors and seniors in mechanical engineering, information technology, and engineering technology. Participation in the Transitional Disaster Shelter competition served as the main project for their Engineering Project Management \& Design course.

\section{Software Integration}

Students enrolled at Pittsburg State University in the School of Construction are exposed to BIM software throughout the curriculum. Students are taught the basics of AutoCAD and Autodesk Revit in their first semester construction graphics course. Subsequent building systems courses build upon that base to include the use of mechanical, structural, and electrical components of Revit. Additional construction method courses cover the inclusion of site work, civil, surveying and framing into the students' software portfolio of understanding. The program includes the option for students to choose a BIM emphasis, allowing for greater in-depth exposure and training in BIM software and how it is utilized and integrated in design and construction management. Project work within the BIM emphasis area consists of model coordination, 
manipulation, and integration utilizing BIM software and the overall project management of implementing BIM on real-world projects as provided by members of our Leadership Council.

Through the introduction and inclusion of a hands-on design-build competitions, students are provided the opportunity to utilize their BIM software skills in the design and construction planning for a project which they then construct and test against their design analysis from the BIM software. The design-build competition also allows students not already in the BIM emphasis to learn new skills and software applications that enabled them to better understand the impacts of their design decisions and the resulting constructability. It should be noted that none of the students on the 2014 or either of the 2015 student teams were enrolled in any of the BIM emphasis courses during the academic year that they were competing. At each phase of the project, students were given a one to two day workshop on the software applications that would be prevalent and beneficial to the current phase of work.

Software utilized in the design phase included:

- AutoCAD

- Sketch-Up

- Autodesk Revit (Architecture, MEP, Structural)
- Autodesk Green Building Studio

- Autodesk Inventor

- Solidworks

- Catia

Students were advised to start out by conducting a design charrette and to sketch out, on the whiteboards within the project meeting space, multiple design concepts and ideas. These initial concept models where then developed from whiteboard sketches into Sketch-Up models for design comparison and design element integration into a working design development model. Sketch-Up provides a very basic level modeling system in a push-pull method environment that allowed the students to quickly give shape to their two dimensional concept sketches. The design development model was then transferred into Autodesk Revit and fleshed out with actual materials. This transition from conceptual design software to material specific modeling roots the students in the real-world properties and limitations of actual building components. With this application of real-world parameters to the project, students were now able to conduct spatial analysis to verify project design requirements. Items that did not have manufacturer provided models, such as specialty products like snap-hinges in addition to off-the-shelf items, were modeled in Autodesk Inventor or Solidworks. Modeling each individual component is essential to the validity of the model results in that the more accurate the model the more accurately it could be used to predict the performance of the final product. The additional part and component modeling provided the students with the opportunity to understand how product families are generated by manufacturers. Moreover, they learned how to model or modify an existing model to the required level of detail when manufacturers' models are not available or do not included the appropriate level of detail in regards to physical dimensions or associated data. The Revit model was then inserted into Autodesk Green Building Studio for building envelope analysis related to structural stability and heat retention. For in-depth investigation and analysis 
of building component interactions (e.g., joints between building panels), analysis models were developed in Autodesk Inventor, Solidworks, and/or Catia. These programs allowed for animated interaction studies and finite element analysis. Alongside the digital model, students were encouraged to build mock-ups of assemblies to verify the constructability of design components and the accuracy of software results.

Software utilized in the project management phase included:

- Microsoft Project

- Autodesk Navisworks

- Synchro

The project managers then developed a project schedule and design estimate in Microsoft Project. The schedule was then integrated along with the design model into Autodesk Navisworks and/or Synchro for 4D project analysis and simulation. Based on the resulting time and cost schedule the teams then proceeded with the construction of their prototype shelters, generating updated models per as-built conditions and field changes. Results from all of the software analyses were then utilized in the development of the project business case analysis, thus aiding in design validation for the student team and project sponsor approval.

\section{Cross-College Interaction and Collaboration}

The College of Technology and School of Construction require all student led construction projects to have a safety management plan in place before any hands-on work may commence. Through collaboration with the EST 496 Construction Safety course a base level safety management plan was developed for each student team. This was beneficial to all parties in that it provided students enrolled in the Environment and Safety Management program the opportunity to apply learned skills to a real-world built project and experience in construction management collaboration and interaction with safety management for the student team project managers. Student teams also worked with the Graphics and Imaging Technology department to develop project branding along with pictographic assembly instructions for the shelter designs. Similar interactions to those with the Environment and Safety Management program were experienced.

\section{Lessons Learned}

Following the conclusion of the Transitional Disaster Shelter competition each year, students were required to give a summary presentation to the faculty of the PSU School of Construction. The following summarizes the lessons learned by the student teams for consideration by university or college teams considering similar efforts: 


\section{Leadership Opportunity for Multi-College/University Collaborative Teams \& Innovation Engineering}

Historically Transitional Disaster Shelter teams have been comprised of students from individual university programs. Based on the experience and knowledge gained through the interactions with other departments in the College of Technology and School of Construction, it would be beneficial to create teams consisting of students from multiple university programs or from multiple universities. These types of teams would benefit from more closely representing the real-world dynamics of multiple partner design-build projects.

Additionally, it would be beneficial to incorporate students into the project teams from the field of Innovation Engineering to aid in the development of the business case analysis and provide an innovative design approach to transitional shelter design applications ${ }^{7}$. Portions of the project requirements could be integrated into the coursework and/or curriculum at educational institutes with an innovation engineering minor or degree program.

\section{Time \& Budget Management}

Similar to outcomes from the CMCET 691 Senior Projects course, students are required to produce time and cost estimates then track their adherence to the proposed schedule and budget. The majority of capstone style courses in construction management programs provide the students with a given program, typically including a client provided design and budget. The variance comes when students need to mock-up prototypes of joints and assemblies in addition to the full scale production of the project. Students working on the Transitional Disaster Shelter competition learned to develop a secondary budget for mock-ups that ran concurrent with the main shelter construction and schedule the mock-ups to allow time for design changes based on the results of those mock-ups.

\section{Institutional and Industry Partnership Support}

Even though the Transitional Disaster Shelter competition emphasized work by students, resources from an entire university and industry partnerships were needed to be successful. In 2014, the School of Construction provided funding for the transportation of the prototype shelter to the competition site at John Brown University and seed funding to facilitate the shelter's construction. Industry partners, key members of the PSU School of Construction Leadership Council, provided construction materials at reduced cost, financial donations, media exposure and design review comments. The University Marketing \& Communications office worked with the student teams to document the design, construction and testing of the shelter and generated news pieces on the competition and student teams, which were then published on the internet via University channels and shared with local news agencies. 


\section{Outcomes of Transitional Disaster Competition}

Several different universities have participated in the Transitional Disaster Shelter competition since it started in 2012. Although each team has a unique approach to the competition and understanding of its value to their home institution, several common outcomes become apparent.

\section{Broader Societal Impacts}

Although it wasn't necessarily obvious at first, everyone on the Transitional Disaster Shelter teams came to appreciate the significance of this project in terms of utilizing their skills to provide a humanitarian effort for their fellow man. One of the proudest moments for students was hearing from project sponsors World Vision and Samaritan's Purse how the work being done in the design-build competition is being used to provide better housing for those in need.

\section{Meet Educational Outcomes}

It is certain that the Transitional Disaster Shelter project will be highlighted when the construction management, construction engineering technology, and environment and safety management programs at Pittsburg State University undergo accreditation renewal in the coming years. The construction management program at Pittsburg State University is one of the first to achieve the ABET accreditation in Construction Management. The Accreditation Board for Engineering \& Technology (ABET) requires that both Technology and Engineering programs incorporate standards and other realistic constraints into their educational programs. The design process for the Transitional Disaster Shelter prototype shelters included not only standards, but also brought economic, environmental, manufacturing, ethics, safety, health, social, teamwork, and marketing issues along with it. It is hard to imagine a better way to expose students to the broad range of issues they will face during their careers.

\section{Industry Collaboration and Research}

The 2014 and 2015 Transitional Disaster Shelter competition helped establish and expand several industry partnerships. Multiple industry partners that began their involvement as a sponsor of one of the shelters have recruited several of our graduates for full time employment opportunities. They have also continued working with faculty on ideas for additional industry involvement and interaction in the classroom.

\section{Community Outreach}

It was a powerful message to the student teams to see how the community embraced their work on the transitional shelter prototypes. On multiple occasions, community leaders would be on hand to witness the setup of the shelter or its construction. Currently, the option to produce additional shelters from the designs of the three prototype shelters currently housed at Pittsburg State University is being considered for donation to local disaster relief organizations in the four states region surrounding Pittsburg, KS, thus providing a means by which the students' work 
may live on and be able to be utilized for their intended purpose. This is similar to the way that many schools competing in the Solar Decathlon in the past have donated their projects to provide low cost housing to their home communities.

Prestige

Although publicity for its own sake was never a stated goal for the project, there is no denying that the visibility of the project has been helpful to the School of Construction, College of Technology, and Pittsburg State University. Media coverage featuring the shelters and students has been utilized by the university and our industry partners for promoting the School of Construction, the humanitarian effort and the values of design-build in education and professional practice. In addition to helping recruit talented new students, the successful outcome of the competition is a source of pride among university administration and loyal alumni.

\section{Conclusions}

The Transitional Disaster Shelter competition is a great opportunity for universities to showcase the talent of their students in a hands-on design-build arena. Students not exposed to BIM in any other forum gain real-world knowledge and experience of implementing BIM in a design-build project. The application of BIM management processes and software on a design-build project where students construct a structure they designed is an invaluable opportunity that can directly apply towards their future careers. Incorporating the competition within a construction management curriculum allows for cross-collaboration between multiple courses (e.g., building information modeling, safety, structures, project management) emulating the collaborative nature of the design-build industry. Faculty and universities who want to compete in this type of design-build competition need to understand the level of commitment required for successful participation. Overall university support is beneficial, but fabrication space is a necessity. Additional support from multiple academic departments and administrative units at the university may also be needed. The event also provides an excellent networking outlet for students and faculty who participate with other academic institutions and humanitarian organizations. However, in the end, the teamwork aspect of the Transitional Disaster Shelter competition might be one of the lasting legacies of the entire project for the institution and student team members.

\section{Acknowledgement}

Participation by Pittsburg State University (PSU) School of Construction student teams in the 2014 and 2015 World Vision/Samaritan's Purse \& John Brown University Transitional Disaster 
Shelter design-build competition was made possible with support from Crossland Construction Company, Inc.; 4W Metal Building Supply, Inc.; Home Depot; and the Pittsburg State University School of Construction.

Participation by the 2015 Gyeongsang National University (GNU) student team in the World Vision/Samaritan's Purse \& John Brown University Transitional Disaster Shelter design-build competition was made possible with support from Gyeongsang National University and the Pittsburg State University's College of Technology, School of Construction, and Department of Technology Workforce Learning.

\section{Bibliography}

1. Bernold, L. E. (2005). Paradigm Shift in Construction Education is Vital for the Future of Our Profession. Journal of Construction Engineering and Management, 131(5), 533-539.

2. Bringle, R. G., \& Hatcher, J. A. (2009). Innovative Practices in Service_learning and Curricular Engagement. New Directions for Higher Education(147), 37-46.

3. DOE. (n.d.). U.S. Department of Energy Solar Decathlon. Retrieved March 1, 2015, from http://www.solardecathlon.gov/

4. Douglas, E. P. (2011). Student Construction of Knowledge in an Active Learning Classroom. American Society for Engineering Education.

5. Fiori, C. M., \& Songer, A. D. (2009). Enhancing Construction Education with Contextual Service Learning. Construction Research Congress 2009, (pp. 1388-1397). Seattle, Washington.

6. JBU. (n.d.). John Brown University: Shelter Contest. Retrieved January 12, 2015, from http://www.jbu.edu/shelter_contest/

7. PSU. (n.d.). Pittsburg State University: Minor in Innovation Engineering. Retrieved February 1, 2015, from http://www.pittstate.edu/college/technology/academic-programs/innovationengineering-minor.dot

8. PSU. (n.d.). Pittsburg State University: School of Constructon. Retrieved February 1, 2015, from http://www.pittstate.edu/department/construction 
9. Rodgers, M., Runyon, D., Starrett, D., \& Von Holzen, R. (2006). Teaching the 21st Century Learner. 22nd Annual Conference on Distance Teaching and Learning, (pp. 1-4). University of Wisconsin, Madison.

10. Sphere Project. (n.d.). The Sphere Project: The Sphere Handbook. Retrieved February 1, 2014, from The Sphere Project: Humanitarian Charter and Minimum Standards in Humanitarian Response: http://www.spherehandbook.org/ 